\title{
Accurate local magnitude prediction for small to moderate earthquakes using rapid calculations of $\boldsymbol{P}$-wave dominant period
}

\author{
Tjipto Prastowo ${ }^{1,2^{*}}$, Berla Maghda Putri Mahanani ${ }^{1}$, Latifatul Cholifah ${ }^{1,2}$, \\ La Ode Ngkoimani ${ }^{3}$, La Ode Safiuddin ${ }^{3}$ \\ ${ }^{1}$ Physics Department, FMIPA, Universitas Negeri Surabaya, \\ Kampus Unesa Ketintang, Surabaya 60231, Indonesia \\ ${ }^{2}$ Research Center for Earth Science Studies, Physics Department, \\ Kampus Unesa Ketintang, Surabaya 60231, Indonesia \\ ${ }^{3}$ Physics Department, FMIPA, Universitas Halu Oleo, \\ Kampus UHO Anduonou, Kendari 92231, Indonesia
}

\begin{abstract}
This study examines mechanisms of rapid and accurate determination of local magnitude $M_{\mathrm{pd}}$ for small to moderate events that occurred in West Sulawesi and Central Sulawesi using direct procedures and calculations of the dominant period $T_{\mathrm{d}}$ of $P$-waveforms. Secondary data were collected from Webdc3, comprising earthquake magnitudes in the regions of interest during 2008-2015 measured in $M \mathrm{w}$. The study focuses on earthquake size estimates for local events as a parameter through simple evaluation of a linear equation relating $T_{\mathrm{d}}$ to $M \mathrm{w}$. For all the events considered, empirical formulas derived from the random data for estimating the size are, respectively, $M_{p d}=\left(T_{d}+6.6799\right) / 1.5199$ for West Sulawesi and $M_{p d}=\left(T_{d}+3.3648\right) / 0.8464$ for Central Sulawesi. Each was used to recalculate events in the two regions. The results were compared to the reference provided by the Global CMT catalog. The results are consistent with the reference having a standard deviation of up to 0.2 , showing evidence of no significant difference in magnitude determination between the method proposed in the current study and that of the Global CMT. This suggests that rapid and accurate magnitude determination is best predicted by the empirical formula developed for each region in this study for future use of disaster risk reduction program.
\end{abstract}

Keywords: dominant period, empirical formula, local magnitude

Received: July 20, 2017; Accepted: September 8, 2017; Published online: October 25, 2017

*Corresponding author: tjiptoprastowo@unesa.ac.id

Citation: Prastowo, T., Mahanani, B. M. P., Cholifah, L., Ngkoimani, L. O., \& Safiuddin, L. O. (2017). Accurate local magnitude prediction for small to moderate earthquakes using rapid calculation of $P$-wave dominant period. Journal of Science and Science Education, 1(2), 15-20.

\section{Introduction}

Hazard assessment relevant to earthquake events includes quick and accurate estimate of the earthquake magnitude. Such invaluable information is vital for preventing local community living in possibly impacted areas from potential damages of structures and possible losses of lives (Shieh et al., 2008; Satriano et al., 2011). Within the context of disaster risk reduction program, the rapid release of public information on the earthquake magnitude has to be accurate because accuracy is one of the two crucial elements required for the development of reliable disaster early warning (Satake, 2014).

Magnitude determination issued by the Indonesian Agency for Geophysics, Climatology, and Meteorology (BMKG), given in terms of $M\llcorner$ and broadly known as a Richter scale, shows lack of 
accuracy when applied to earthquakes with large magnitudes (McCalpin, 2010). A method of moment magnitude $M_{\mathrm{w}}$ with better accuracy is globally used for multiple events, independent of the event size, although it takes a long time to complete calculation. Another method technically developed for effective earthquake-tsunami alerts, namely $M_{\text {wpd }}$, was introduced by Lomax \& Michelini $(2011,2012)$ to include measurements of the $P$-wave dominant period. Applying this to two cases with large sizes in Sumatra, Madlazim (2013) could resolve different tsunami warnings. Further revisions for better prediction of disastrous events were made using programming codes called Joko Tingkir (Madlazim et al., 2015). A comprehensive evaluation of earthquake parameters in the existing tsunami early warning system (Ina-TEWS) in the country was set in accordance with Joko Tingkir for local tsunamigenic earthquakes (Madlazim \& Prastowo, 2016).

However, there have been no previous studies on rapid and accurate local earthquake magnitude determination using field information recorded at nearby seismic station network in Indonesian eastern provinces. In this study, we examine local earthquakes and then aim to derive the empirical formula for the corresponding local event magnitude $M_{\text {pd }}$ using rapid calculations of the dominant period $T_{\mathrm{d}}$ extracted from $P$-wavelets. The specific aim is to search for a method reliable for quick and accurate estimate of local occurrences in both West and Central Sulawesi to reduce, if not to prevent society from, the possible losses of properties and lives to a minimum level. These regions of interest are chosen since local seismo-tectonic movement are claimed active with the corresponding hypocenters being shifted to the surrounding seas, potential to tsunami generation (Baeda, 2011) although new findings in the regions suggest that underground fault movement could also be very active (Kompas, 31 Mei 2017).

\section{Methods}

A total of 37 local earthquakes in West Sulawesi and its surroundings with hypocenters below the seas and lands having magnitudes in the range $4.0 \leq M \leq 7.5$ during 2008-2015 were analyzed as the first case to examine and a total of 50 local seismic events in Central Sulawesi and its perimeter with other parameters being similar were examined as the second case in this study. Geographical positions of the two regions are respectively $0.20^{\circ}-3.63^{\circ} \mathrm{S}$ and $118.72^{\circ}-124.90^{\circ} \mathrm{E}$ for West Sulawesi and $2.37^{\circ} \mathrm{N}-3.80^{\circ} \mathrm{S}$ and $119.37^{\circ}-124.37^{\circ} \mathrm{E}$ for Central Sulawesi. In all cases considered, the events are mostly initiated by sources at shallow depths of $\leq 100 \mathrm{~km}$.

All the events were freely downloaded as high-frequency broadband seismograms from http://eida.gfz-potsdam.de/webdc3/ and http://www.globalcmt.org/. The signals were analyzed using SeisGram2K available at http://alomax.free.fr/seisgram/SeisGram2K.html. All sizes obtained from Webdc3 were named as $M_{\mathrm{w}}$ while those from the Global CMT catalog of the same events were termed as $M_{\mathrm{w}}{ }^{\mathrm{CMT}}$ for direct comparison. Since there was no significant difference between the two measures of magnitude, we utilized $M_{\mathrm{w}}$ for rapid calculations of $T_{\mathrm{d}}$ using Joko Tingkir and used $M{ }^{C M T}$ for the magnitude reference.

All magnitudes of the local occurrences obtained in the two provinces were reported as $M_{\text {pd }}$ used to develop an empirical formula for each region of interest. Therefore, we examine if there is agreement between rapid determination of the local earthquake magnitudes using the method proposed in this study and magnitudes of the same events provided by the Global CMT catalog. By doing this test, we examine accuracy of the current method for magnitude determination in comparison to the magnitude reference given by the Global CMT catalog. 


\section{Results and Discussion}

The observed magnitudes from 37 shallow sources of local occurrences with hypocentres below the sea surface and on land at some depth observed by a network of local seismic stations in West Sulawesi and other 50 similar events occurred in Central Sulawesi during 2008-2015 were collected from Webdc3 and the Global CMT sites and measured as $M_{\mathrm{w}}$ and $M_{\mathrm{w}}{ }^{\mathrm{CMT}}$, respectively. Using these magnitude measures, relatively small values of 0.14 and 0.17 of standard deviation were then obtained for West Sulawesi and Central Sulawesi, respectively. This allows us to rapidly calculate $T_{d}$ using magnitudes either scaled with $M_{\mathrm{w}}$ or $M_{\mathrm{w}}{ }^{\mathrm{CMT}}$ with, in the limit of the uncertainty of the measurements, no significant difference in the calculated results.

We here provide plots of all earthquakes recorded at local seismic stations for each case study (West Sulawesi on the left panel and Central Sulawesi on the right panel) in Figure 1 below, where all the $M_{\mathrm{w}}$ data were collected from Webdc3 and their corresponding dominant periods $T_{\mathrm{d}}$ were rapidly calculated using Joko Tingkir programming codes (Madlazim et al., 2015). Note that we examine from the plots whether or not the dominant period $T_{\mathrm{d}}$ shows a positive correlation to the measured magnitude $M_{\mathrm{w}}$.
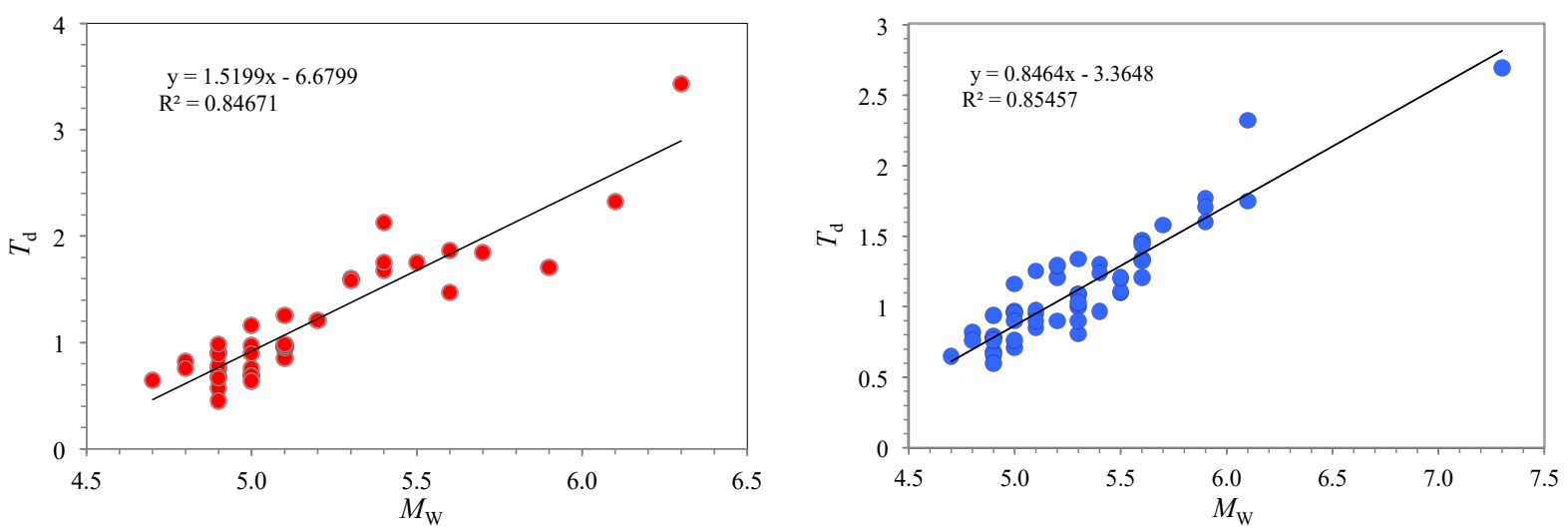

Figure 1. Plots of all 37 occurrences in West Sulawesi (left) and 50 events in Central Sulawesi (right) during 2008-2015 with magnitudes in the range $4.0 \leq M \leq 7.5$, giving a linear trend between the dominant periods $T_{\mathrm{d}}$ measured in seconds and magnitudes measured as $M_{\mathrm{w}}$ by Webdc3 with lines of best fit and their corresponding equations for each region.

There is a similarity in trend between the two plots in Figure 1, indicating a persistent model for a likely linear trend between $T_{\mathrm{d}}$ and $M_{\mathrm{w}}$ with a correlation coefficient of $\mathrm{R} \approx 0.92$ for both plots. This trend was also obtained by Shieh et al. (2008) using different field data of the Japanese events. It follows that $T_{\mathrm{d}}$ increases with increasing sizes $M_{\mathrm{w}}$ of local sources. As the earthquake magnitude is a measure of how strong an event strikes and influences its surrounding areas, it appears that $T_{\mathrm{d}}$ could become one of crucial parameters (Lomax and Michelini, 2011; 2012; Madlazim, 2013) that provides a clue if the earthquake is dangerous. Using an inverted linear trend in Fig. 1, we derive an empirical formula for predicting earthquake sizes of future local events that may occur in Sulawesi. Regarding the line for the West Sulawesi region, the empirical formula is given by

$$
M_{\mathrm{pd}}=\left(T_{\mathrm{d}}+6.6799\right) / 1.5199
$$

where we have replaced $M_{\mathrm{w}}$ with $M_{\mathrm{pd}}$ remembering that the sources used in the present study are of local occurrences, and then for the Central Sulawesi region the formula is given by

$$
M_{p d}=\left(T_{d}+3.3648\right) / 0.8464
$$


From all sources examined in each region, the sizes calculated using Eq. (1) and Eq. (2) are in good agreement with values given by Webdc 3 and the Global CMT catalog measured as $M_{w}$ and $M_{w}{ }^{C M T}$. Relatively compared to $M_{\mathrm{w}}{ }^{\mathrm{CMT}}$ as the reference, small values of standard deviation of 0.13 and 0.16 were obtained for each case. Approximately the same standard deviation was also obtained when the results are compared to magnitudes in $M_{\mathrm{w}}$. It means that the formulas for $M_{\mathrm{pd}}$ of local seismic events in both Eq. (1) and Eq. (2) can therefore be, to first order, used to predict an earthquake size in both West and Central Sulawesi, respectively, with some limitation.

Figure 2 provides direct comparison between the results of magnitude determination for both provinces using the present method and those given by the Global CMT catalog. Two plots in Figure 2 clearly show accurate estimates of earthquake magnitudes $M_{p d}$ derived from local sources of moderate magnitudes in majority that occurred in West and Central Sulawesi for a period of 20082015 years. The estimates of magnitude are directly determined from Eqs. (1) and (2) using the $T_{\mathrm{d}}$ data available. In regard to small values of 0.13 and 0.16 found for standard deviation of the scatter for each region, we suggest that the method proposed is, to some extent, applicable to cases where earthquake events are localized at a distance of no more than 1100 kilometers away from the epicenter, and hence are recorded at local stations nearby. The discrepancies in the magnitudes between estimates using the proposed method and those of the reference given by the Global CMT catalog are insignificant. The results for the estimates for both provinces are therefore sufficiently accurate and are, considering the relatively small errors in the estimates, consistent with previous work (Shieh et al., 2008; Lomax and Michelini, 2011).
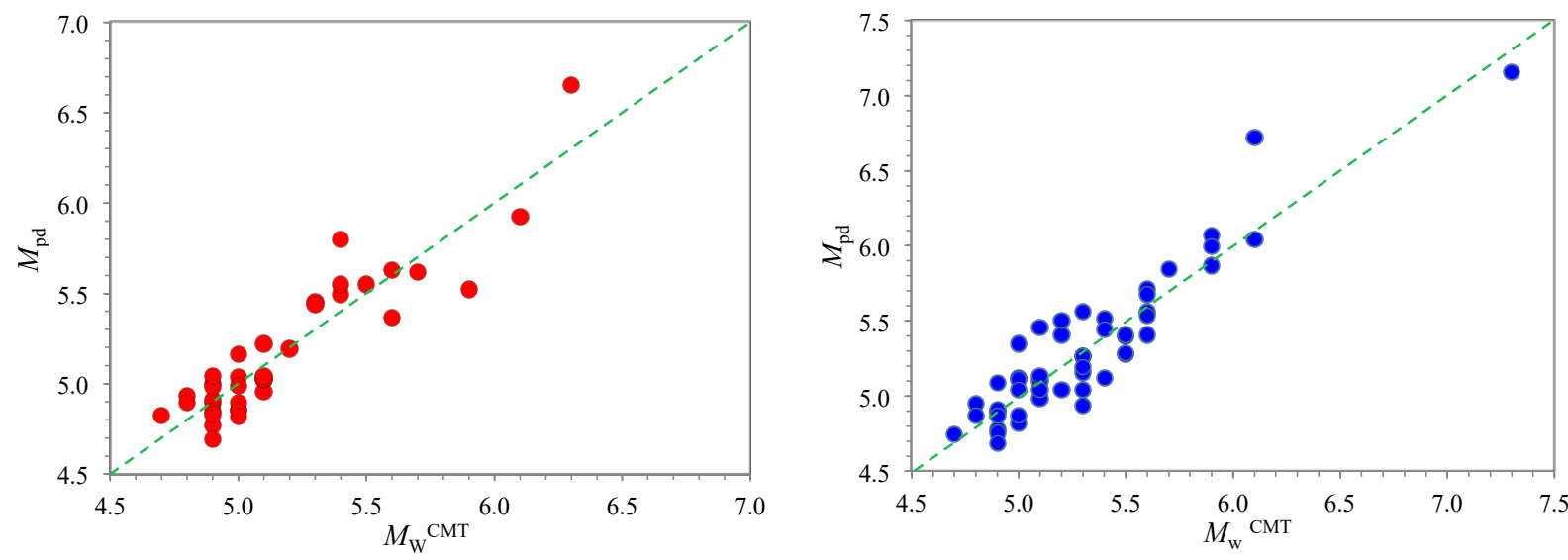

Figure 2. Plots of all 37 occurrences in West Sulawesi (left) and 50 events in Central Sulawesi (right) during 2008-2015 scaled with two different methods, showing no significant discrepancy between $M_{\text {pd }}$ measured by the current method and $M_{w}{ }^{C M T}$ provided by the Global CMT catalog. Red and blue full-circles describe the scattered data for each case where $4.0 \leq M \leq 7.5$, with the circles in the green dashed-line representing events of the same size measured.

As thoroughly discussed by Baeda (2011), some areas in Sulawesi island including West and Central Sulawesi are potential to dreadful disasters. This is due to increasing seismic activities and shifted trends in the hypocenters from lands to seas at depth in the regions, making the island with very long shorelines vulnerable to tsunamigenic earthquakes. In line with various techniques developed for better prediction, rapid and accurate magnitude determination is of fundamental importance to minimize negative impacts on society, such as reduction in fatalities by preventing local people from false early warnings (Satriano et al., 2011; Lomax \& Michelini, 2011, 2012; Madlazim et al., 2015; Madlazim \& Prastowo, 2016). Although the results for the datasets used in this study are limited to moderate events occurring in localized areas of research, the method proposed is argued 
for testing to different regions in the Indonesian archipelago. It follows that research on rapid and accurate magnitude determination in the context of disaster risk reduction remains important due to seismo-tectonic activities along the Sunda Arc over recent decades.

\section{Conclusion and Remarks}

Rapid and accurate assessment on the magnitude of an earthquake plays a vital role in minimizing possible fatalities following a geophysical hazard. The magnitude $M_{p d}$ of a local event is determined using analyses of $P$-seismic waveforms and rapid calculations of $T_{\mathrm{d}}$ observed at a network of local seismic stations. The cases considered in the present study are events in both West and Central Sulawesi between 2008 and 2015 with magnitudes in the range $4.0 \leq M \leq 7.5$. Using the datasets available, the results for all such occurrences lead to the empirical formula, $M_{\mathrm{pd}}=\left(T_{\mathrm{d}}+\right.$ 6.6799)/1.5199 for West Sulawesi and $M_{p d}=\left(T_{d}+3.3648\right) / 0.8464$ for Central Sulawesi. Magnitude estimates in the regions result in insignificant discrepancies between values estimated by the proposed method and those provided by the Global CMT catalog with a relatively small standard deviation of up to 0.2 . In the context of hazard mitigation study developed in Indonesia, particularly in the eastern provinces the results are used to help central and local government understand the science of disaster and thereby reducing disaster risks. Therefore, efforts made for earthquake early warning, either local or regional, hence early warning system development may better use quick information with adequate accuracy from a network of local stations only.

\section{Acknowledgment}

The authors would gratefully like to thank anonymous reviewer(s) of the 2017 IConSSE for valuable comments upon the paper. Along with discussion during the conference parallel session, all suggested comments are appreciated for clarity and completeness of the paper required for publication in JOSSE. The authors also express gratitude to Prof. Dr. Ir. Usman Rianse, M.S. as Rector of UHO for his decision at the closing ceremony of the 2014 CICES held in Kendari to provide adequate financial supports. Prof. Dr. Madlazim, M.Si is appreciated for his great help in accessing and collecting the data. Dyah Ayu Puspitasari, Muhammad Firdaus, and Wahidussilmi are also appreciated for their unshakable commitment and best accompanying times as well as other crews in the workshop laboratory during the completion of the work.

\section{References}

Shieh, J. T., Wu, Y. M., \& Allen R. M. (2008). A comparison of $\tau_{c}$ and $\tau_{c}{ }^{\text {max }}$ for magnitude estimation in earthquake early warning. Geophysical Research Letters, 35, 1-5.

Satriano, C., Wu, Y. M., Zollo, A., \& Kanamori, H. (2011). Earthquake early warning: concepts, methods, and physical grounds. Soil Dynamics and Earthquake Engineering, 31(2), 106-118. https://doi.org/10.1016/j.soildyn.2010.07.007

Satake, K. (2014). Advances in earthquake and tsunami sciences and disaster risk reduction since the 2004 Indian ocean tsunami. Geoscience Letters, 1, 1-13.

McCalpin, J. P. (2010). Appendix 1: Earthquake Magnitude Scales. GEO-HAZ Consulting Inc. Crestone, Colorado 81131.

Lomax, A., \& Michelini, A. (2011). Tsunami early warning using earthquake rupture duration and $P$-wave dominant period: the importance of length and depth of faulting. Geophysical Journal International, 185, 283-291.

Lomax, A., \& Michelini, A. (2012). Tsunami early warning within five minutes. Pure and Applied Geophysics, 170( 9-10), 1385-1395. https://doi.org/10.1007/s00024-012-0512-6 
Prastowo, Mahanani, Cholifah, Ngkoimani, \& Safiuddin: Accurate local magnitude prediction for small to moderate earthquakes using rapid calculation of $P$-wave dominant period

Madlazim (2013). Assessment of tsunami generation potential through rapid analysis of seismic parameters - case study: comparison of the Sumatra earthquakes of 6 April and 25 October 2010. Science of Tsunami Hazards, 32, 29-38.

Madlazim, Prastowo, T., \& Hardy, T. (2015). Validation of Joko Tingkir software using tsunami importance. Science of Tsunami Hazards, 34, 189-198.

Madlazim, \& Prastowo, T. (2016). Evaluation of earthquake parameters used in the Indonesian tsunami early warning system. Earthquake Science, 29, 27-33.

Baeda, A. Y. (2011). Seismic and tsunami hazard potential in Sulawesi Island Indonesia. Journal of International Development and Cooperation, 17, 17-30.

The Germany Government, Geoforschungs Zentrum (GFZ), Helmholtz-Zentrum Postdam. (2016). Retrieved from http://eida.gfz-potsdam.de/webdc3/.

The Global Centroid-Moment-Tensor web page. (2016). Retrieved from http://www.globalcmt.org/.

Anthony A. Lomax's home page. (2016). Retrieved from http://alomax.free.fr/seisgram/SeisGram2K.html. 